\title{
Papiledema en hipertensión intracraneana idiopática
}

\section{Papilledema in idiopathic intracranial hypertension}

Jorge E. Morales-León* y Lorena Romero-Díaz-De-León

Oculab, Aguascalientes, México

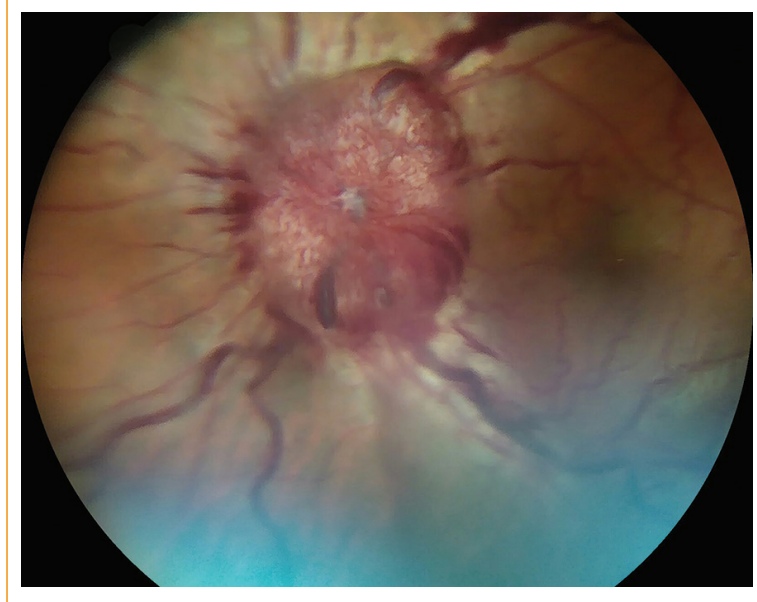

Figura 1. Imagen estéreo 1 del ojo izquierdo.

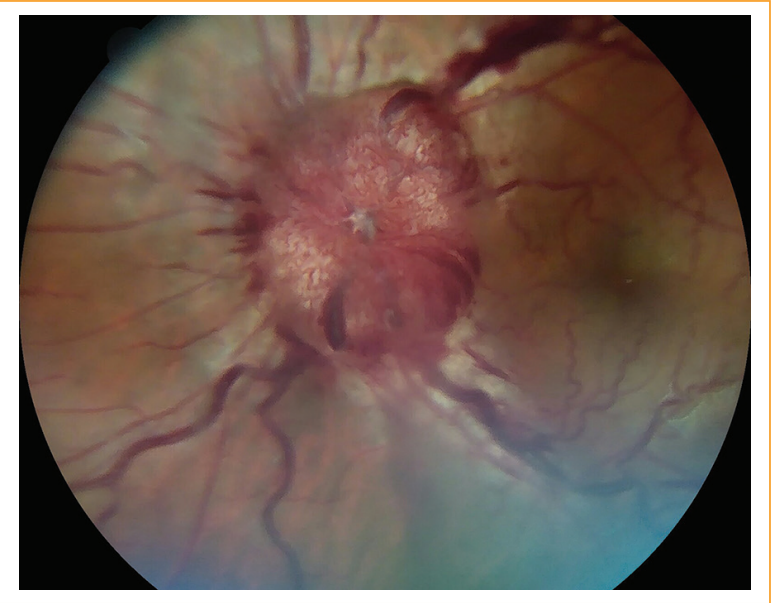

Figura 2. Imagen estéreo 2 del ojo izquierdo.

Se trata de una imagen de papiledema bilateral en un paciente de 40 años que acudió con cefaleas y aumento de mancha ciega en la exploración con pantalla tangente. Se encontró la imagen fundoscópica que se presenta en las Figuras 1-4.

\section{Financiamiento}

Los autores declaran no haber recibido financiamiento para este estudio.

\section{Conflicto de intereses}

Los autores declaran no tener conflicto de intereses.

\section{Responsabilidades éticas}

Protección de personas y animales. Los autores declaran que para esta investigación no se han

Correspondencia:

*Jorge E. Morales-León

República de Ecuador 103. Torre Médica Quality

2do piso C. P. 20230, Aguascalientes,

Fecha de recepción: 15-08-2020

Aguascalientes, México

E-mail: oculab.aguascalientes@gmail.com

0187-4519/@ 2021 Sociedad Mexicana de Oftalmología. Publicado por Permanyer. Este es un artículo open access bajo la licencia CC BY-NC-ND (http://creativecommons.org/licenses/by-nc-nd/4.0/).
Disponible en internet: 25-10-2021

Rev Mex Oftalmol. (ahead of print)

www.rmo.com.mx
Fecha de aceptación: 24-02-2021 
Rev Mex Oftalmol. (ahead of print)

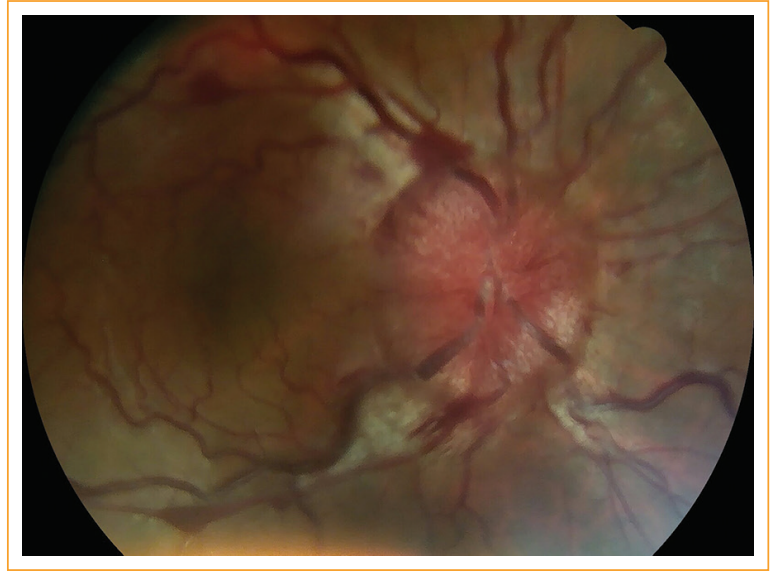

Figura 3. Imagen estéreo 1 del ojo derecho.

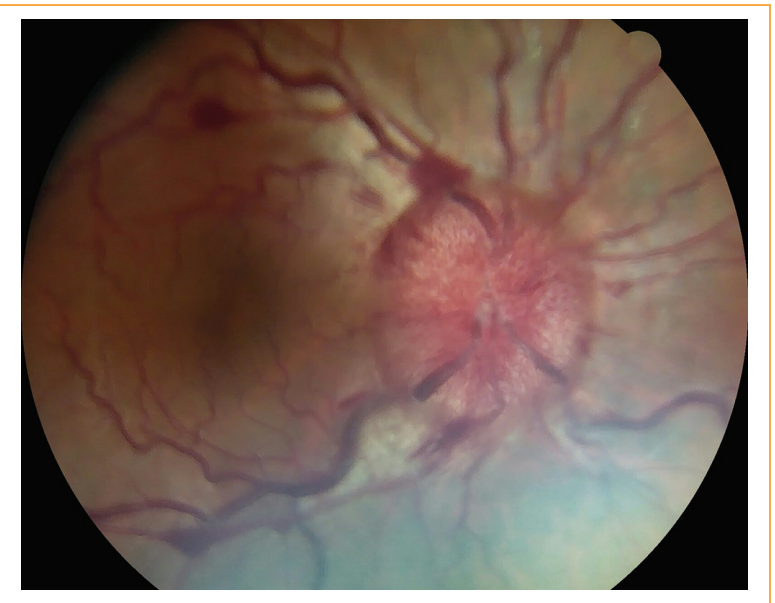

Figura 4. Imagen estéreo 2 del ojo derecho. realizado experimentos en seres humanos ni en animales.

Confidencialidad de los datos. Los autores declaran que han seguido los protocolos de su centro de trabajo sobre la publicación de datos de pacientes.
Derecho a la privacidad y consentimiento informado. Los autores han obtenido el consentimiento informado de los pacientes y/o sujetos referidos en el artículo. Este documento obra en poder del autor de correspondencia. 